\title{
Early Favorable Non-Hodgkin Lymphoma
}

National Cancer Institute

\section{Source}

National Cancer Institute. Early Favorable Non-Hodgkin Lymphoma. NCI Thesaurus.

Code C53280.

A clinical stage I or II non-Hodgkin lymphoma without any of the following risk factors:

large mediastinal mass, extranodal spread, elevated erythrocyte sedimentation rate, involvement of at least three lymph node areas, and B symptoms. 